\title{
INCIDENCE OF SPONTANEOUS ABORTIONS AND CONGENITAL ANOMALIES IN THE VICINITY OF A URANIUM PROCESSING PLANT
}

\author{
Jitka Jírová1, Zuzana Michalová1, Ladislav Beránek², Květoslava Kotrbová3, Friedo Zölzer ${ }^{4}$ \\ ${ }^{1}$ Institute of Health Information and Statistics of the Czech Republic, Prague, Czech Republic \\ 2Department of Applied Mathematics and Informatics, Faculty of Economics, University of South Bohemia in České Budějovice, České \\ Budějovice, Czech Republic \\ ${ }^{3}$ Institute of Laboratory Diagnostics and Public Health, Faculty of Health and Social Sciences, University of South Bohemia in České Budějovice, \\ České Budějovice, Czech Republic \\ ${ }^{4}$ Institute of Radiology, Toxicology, and Civil Protection, Faculty of Health and Social Sciences, University of South Bohemia in České \\ Budějovice, České Budějovice, Czech Republic
}

\section{SUMMARY}

Objectives: The exposure of embryos or foetuses to ionising radiation can cause serious detriments to health. Thus, an enhanced incidence of spontaneous abortions and congenital anomalies might be expected in the vicinity of a uranium processing plant. We analysed the situation in the vicinity of MAPE Mydlovary, a facility about $20 \mathrm{~km}$ from České Budějovice, South Bohemia, Czech Republic, which was in operation from 1963 to 1992.

Methods: No relevant data are available for the period of operation of the uranium processing plant. Statistical data have only been collected since 1994. As sanitation work in the area was initiated at around that time and has yet to be completed, we considered a study of possible prenatal effects in the vicinity of MAPE Mydlovary to still be of interest. Data were provided by the Institute of Health Information and Statistics of the Czech Republic for the years 1994-2013.

Results: We tested whether there are demonstrable, statistically significant differences between the microregions of the four closest villages (Mydlovary, Olešník, Zahájí, and Zliv), the District of České Budějovice, the South-Bohemian Region, and the Czech Republic.

Conclusions: No increase was found in the incidence of spontaneous abortions and congenital anomalies in the vicinity of this former uranium processing plant compared to the surrounding District of České Budějovice, the South Bohemian Region, or the Czech Republic as a whole.

Key words: uranium mining, uranium milling, radiation, prenatal development, embryo, foetus

Address for correspondence: F. Zölzer, Institute of Radiology, Toxicology and Civil Protection, Faculty of Health and Social Sciences, University of South Bohemia in České Budějovice, České Budějovice Hospital, Boženy Němcové 54, 37005 České Budějovice, Czech Republic. E-mail: zoelzer@zsf.jcu.cz

https://doi.org/10.21101/cejph.a4977

\section{INTRODUCTION}

Ionising radiation is a well-known teratogen. While exposure during the pre-implantation period is predominantly an "all or nothing" phenomenon leading to either abortion or healthy offspring, later exposure during embryogenesis, especially during organ development, can lead to growth restriction or malformation, and exposure during the foetal stage can cause severe mental retardation (1). Only the latter has been documented in humans, i.e. with people exposed in utero during the atomic bomb explosion in Hiroshima and Nagasaki (2). The other effects mentioned have been observed in animal experiments (3). All these effects are induced only with radiation doses exceeding a so-called threshold dose, which stands at about $50 \mathrm{mGy}$ for malformation, and somewhat higher for severe mental retardation, depending on the time during pregnancy (4). The effects of internal exposure to uranium on prenatal brain development have also been described, again in animal experiments, but it has been suggested that these are heavy metal effects rather than the effects of radiation exposure (5).

MAPE Mydlovary was the main facility for chemical processing of uranium ores in former Czechoslovakia. It was in operation from 1963 to 1992. In the course of these years, about 16.7 million tons of uranium ore were processed. Residual materials from the elution process containing 2,800 tons of uranium were dumped into waste ponds covering an area of more than 280 ha. The villages Mydlovary, Olešník, Zahájí and Zliv are situated in the immediate vicinity of the MAPE facility and its waste ponds (at a distance of 1,2, 2 and $5 \mathrm{~km}$, respectively) (Fig. 1). The inhabitants of these villages were exposed (and to a certain extent are still exposed) to radioactive substances, but also to heavy metals and possibly other factors (6). Aside from the exposure of employees (who were mainly from the nearby villages) during their work at the processing plant (7), exposure of the local population might be caused by dust from the unloading of trucks, from the milling 
process, or from a partial drying-out of waste ponds, which could be stirred up by winds and transported to the mentioned villages.

As prenatal effects occur due to the exposure of the embryo or foetus itself, and as there is only limited evidence for effects of radiation exposure on parents (1), one would expect an increased frequency of abortions and congenital anomalies during the time when the MAPE processing plant was in operation rather than years later. Unfortunately, pertinent data are not available at the Institute of Health Information and Statistics of the Czech Republic. The kinds of statistics that are required have only been collected since 1994. Because sanitation work around MAPE had just begun at that time (and is yet to be completed), we still considered it useful to investigate possible prenatal effects in the four villages in the vicinity.

The aim of the analysis was to test possible differences in the incidence of congenital anomalies and spontaneous abortions in the following areas: the four closest villages to MAPE - Mydlovary, Olešník, Zahájí and Zliv; the District of České Budějovice to which these villages belong; the South Bohemian Region; the Czech Republic as a whole (Fig. 1).

\section{MATERIALS AND METHODS}

\section{Basic Data on Spontaneous Abortions}

The numbers of spontaneous abortions were taken from the National Register of Abortions, which is administered by the Institute of Health Information and Statistics of the Czech Republic. Data collected from 1994 to 2013 were available in electronic form from this source. In order to compare regions of different sizes, the incidence of spontaneous abortions was expressed as the ratio of their number to the total number of pregnancies for each particular year. In accordance with the definition of the Czech Statistical Institute, the number of pregnancies was calculated as a sum of abortions (all types of abortions) and deliveries (of both alive and dead children). This raw calculation of the average can be affected by the age structure in the particular regions. In particular, the number of abortions and total number of deliveries are usually influenced by the number of women at reproductive age. To avoid possible errors in the comparison of regions resulting from unequal age structures, we carried out a standardisation based on the age structure in the Czech Republic in each particular year. These standardised parameters were then used for further analysis.

\section{Basic Data on Congenital Anomalies}

We used information from the Institute of Health Information and Statistics of the Czech Republic regarding numbers of congenital anomalies in children born (both alive and dead) between 1994 and 2013. The incidence of congenital anomalies was calculated as the ratio of their number to the number of children born (both alive and dead). We also carried out the standardisation based on the age structure in the Czech Republic in each particular year, compensating for possible differences resulting from unequal age structures in the regions compared.

\section{Method of Statistical Testing}

The aim of this study was to test statistical differences between the regions chosen, regarding spontaneous abortions and congenital anomalies, and in this way to assess the possibility that the operation of the uranium processing plant of MAPE Mydlovary affected population health in the nearby villages.

In order to test differences between regions, the analysis of variance method (ANOVA) was applied. The distribution of the measured data was expected to be positively skewed (Poisson distribution), hence the dependent variable was modified with the help of a logarithmic transformation (for the standardised parameter of the incidence of spontaneous abortions) or with the help of a square-root transformation (in the standardised parameter of the incidence of congenital anomalies). After ANOVA, a post-hoc Tukey test was performed. The accuracy of the models employed was controlled with the help of regression analysis. We then looked for statistically significant differences between

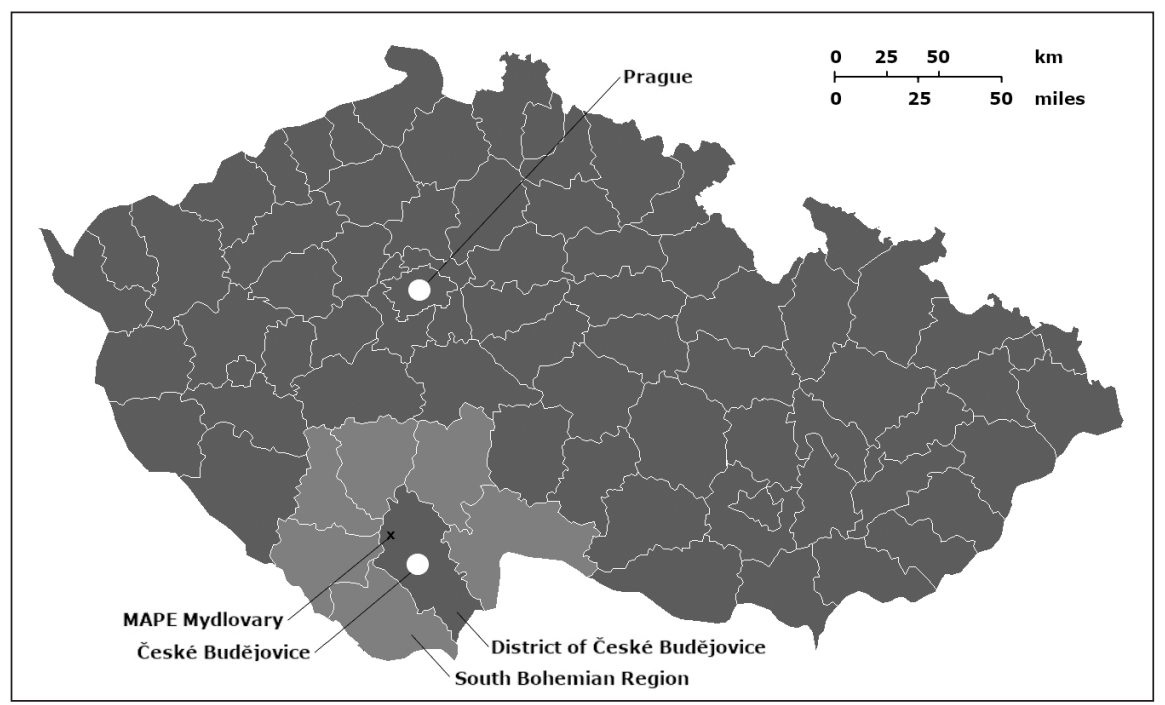

Fig. 1. Schematic map of the Czech Republic showing the South Bohemian region (light grey), the district of České Budějovice (dark grey), and the location of the uranium processing plant MAPE Mydlovary.

Region 1 - villages closest to MAPE Mydlovary, Region 2 - District of České Budějovice, Region 3 - South Bohemian region, Region 4 - the Czech Republic as a whole 
the regions in the ratio of the number of spontaneous abortions to the total number of pregnancies, or in the ratio of deliveries with congenital anomalies to the total number of children born.

For statistical analysis the individual groups which are compared should ideally be entirely independent of each other, whereas in our case the test region (villages in the vicinity) is part of the District of České Budějovice, of the South Bohemian Region, and of the Czech Republic. However, because the absolute numbers of spontaneous abortions and congenital abnormalities in the test region are small, this non-independence is assumed to be of negligible influence on the outcome of any of the comparisons below.

\section{RESULTS AND DISCUSSION}

\section{Incidence of Spontaneous Abortions}

Data on the incidence of spontaneous abortions for each region were available for the period of 1994 to 2013. For a graphical representation of average annual values in the different regions see Fig. 2. Due to the smallness of the numbers, the variability from year to year was much greater in Region 1 (villages closest to MAPE Mydlovary), but everywhere there seemed to be an increase in spontaneous abortions with time.

In comparing the different regions, we were able to demonstrate statistically significant differences. As seen in Fig. 3, the incidence of spontaneous abortions was smallest in Region 1 (the nearby villages) and highest in Region 2 (District of České Budějovice). The post-hoc Tukey test was employed to show that this difference was statistically significant $(p=0.010)$. It should be mentioned, however, that in actual figures the difference is quite small. Whereas the standardised rate of spontaneous abortions in Region 1 was 0.070 per pregnancy, it was 0.094 in Region 2 . The other differences, in particular those between Region 1 and the South Bohemian Region or the Czech Republic as a whole were not significant $(\mathrm{p}>0.05)$.

We also assessed whether the above-mentioned temporal trend in the incidence of spontaneous abortions was real (Fig.
2). The correlation with time was most obvious on the national level, i.e. for Region 4, and turned out to be highly significant $(\mathrm{p}<0.001)$. The absolute difference between the years 1994 and 2013 was about 3,000 abortions (11,000 in 1994 and 14,000 in 2013). During this time there was a corresponding increase in the standardised rate of spontaneous abortions per pregnancy $(0.064$ in 1994 and 0.095 in 2013).

\section{Incidence of Congenital Anomalies}

The number of congenital anomalies in children born for each region was also available for the period of 1994 to 2013. For a graphical representation of average annual values in the different regions see Fig. 4. Again, there was some variability, especially in Region 1 (the villages closest to MAPE Mydlovary) (Fig. 1). We observed an extreme value in 1998 and elevated values in 2007 and 2012. However, these are most likely just local oscillations, due to small numbers.

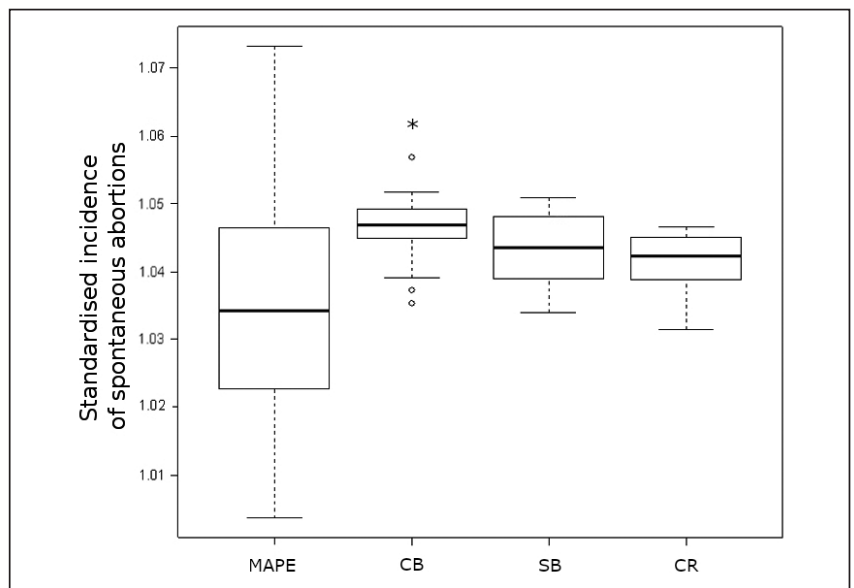

Fig. 3. Standardised incidence of spontaneous abortions between 1994-2013 depending on the region.

MAPE - nearby villages of Mydlovary, Olešník, Zliv and Zaháji; CB - České Budějovice District; SB - South-Bohemian Region; CR - Czech Republic

${ }^{*}$ There was a statistically significant difference between this region and the villages in the vicinity of MAPE Mydlovary $(p<0.05)$.

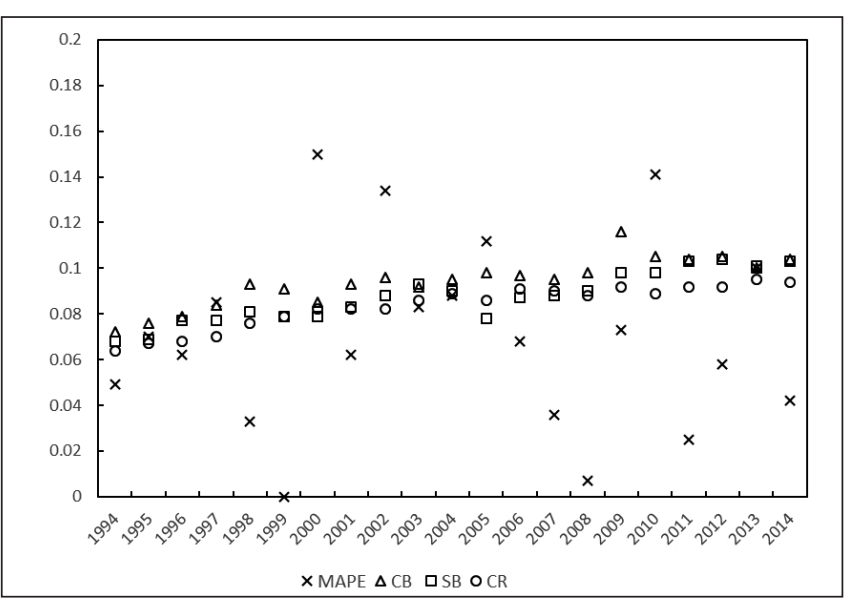

Fig. 2. Proportion of spontaneous abortions among all pregnancies in the period 1994-2013.

MAPE - nearby villages of Mydlovary, Olešník, Zliv and Zaháji; CB - České Budějovice District; SB - South-Bohemian Region; CR - Czech Republic

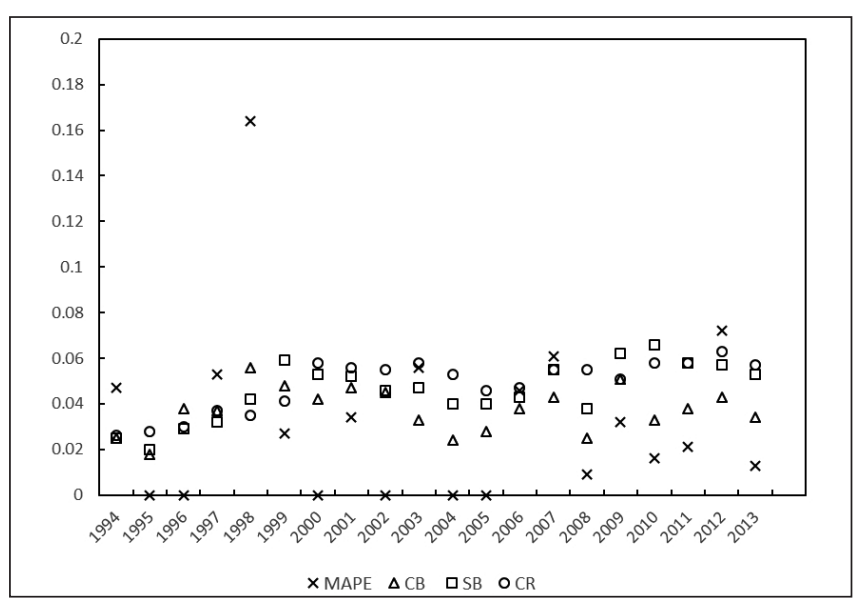

Fig. 4. Proportion of congenital anomalies among all live births between 1994 and 2013.

MAPE - nearby villages of Mydlovary, Olešník, Zliv and Zahájí; CB - České Budějovice District; SB - South-Bohemian Region; CR - Czech Republic 


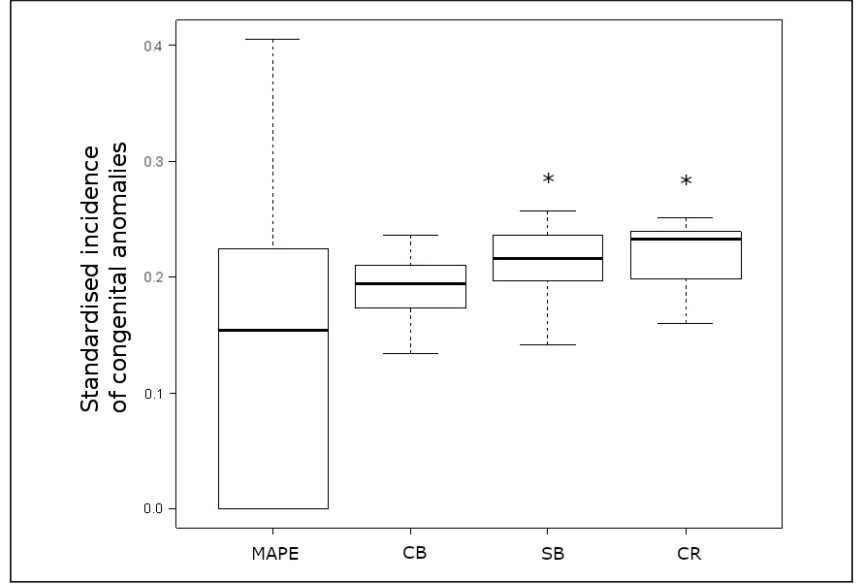

Fig. 5. Standardised incidence of congenital anomalies in the period of 1994 to 2013 depending on the region.

MAPE - nearby villages of Mydlovary, Olešník, Zliv and Zahájí; CB - České Budějovice District; SB - South-Bohemian Region; CR - Czech Republic *There was a statistically significant difference between these regions and the villages in the vicinity of MAPE Mydlovary $(p<0.05)$ statistically significant differences. As seen in Fig. 5, the incidence of congenital anomalies obviously, and against expectation, increased from Region 1 (the villages closest to MAPE) to Region 4 (the whole Czech Republic). The post-hoc Tukey test was used to identify which differences were statistically significant. We demonstrated statistically significant differences between Region 1 and Region 4, i.e. between the villages of Mydlovary, Olešník, Zliv and Zahájí on the one hand and the Czech Republic as a whole on the other, and between Region 1 and Region 3, i.e. between the nearby villages and the South Bohemian Region $(p=0.002$ and $\mathrm{p}<0.001$, respectively). Again, although our analysis revealed statistically significant differences between the regions, in actual figures the differences were not that big: whereas in Region 1 the standardised rate of congenital abnormalities was 0.033 per live birth, in Regions 3 and 4 it was 0.046 and 0.048 , respectively. The significance level between Region 1 and Region 2 (District of České Budějovice) was just above 0.05 , which could be called marginally significant $(\mathrm{p}=0.053)$.

We also attempted to find a temporal trend in the incidence of congenital anomalies. However, at a 95\% confidence level, it was impossible to demonstrate a correlation with time $(p=0.061)$.

\section{CONCLUSION}

This study addressed the question of possible impacts of a uranium processing plant on the health of the surrounding population. Based on the available data, we tested possible differences in the incidence of spontaneous abortions and congenital anomalies between the nearby villages (Mydlovary, Olešník, Zliv and Zahájí), district, region, and the whole country. Although we did find differences that were statistically significant, in absolute terms they were quite small and, more importantly, they were always in favour of the people in the immediate vicinity of the uranium processing plant, i.e. higher incidences were found in the district (spontaneous abortions) or in the region and the whole country (congenital anomalies).

\section{Acknowledgements}

This research has been supported by the Faculty of Health and Social Studies, University of South Bohemia (Project EPZ2012_003).

\section{Conflict of Interests}

None declared

\section{REFERENCES}

1. De Santis M, Cesari E, Nobili E, Straface G, Cavaliere AF, Caruso A Radiation effects on development. Birth Defects Res C Embryo Today. 2007;81(3):177-82.

2. Otake M, Schull WJ, Lee S. Threshold for radiation-related severe mental retardation in prenatally exposed A-bomb survivors: a re-analysis. Int J Radiat Biol. 1996;70(6):755-63.

3. International Commission on Radiological Protection. Pregnancy and medical radiation. Ann ICRP. 2000;30(1):1-43.

4. Streffer C, Shore R, Konermann G, Meadows A, Uma Devi P, Preston Withers J, et al. Biological effects after prenatal irradiation (embryo and fetus). A report of the International Commission on Radiological Protection. Ann ICRP. 2003;33(1-2):5-206

5. Domingo JL. Reproductive and developmental toxicity of natural and depleted uranium: a review. Reprod Toxicol. 2001;15(6):603-9.

6. Havránková R, Havránek J, Kaňkovský J, Řepa L, Zölzer F. The radiological situation around the former uranium processing plant MAPE Mydlovary, Czech Republic. Nucl Technol Radiat Prot. 2015;30(2):132-8.

7. Havránková R, Freitinger Skalická Z, Havránek J, Novotná D, Zölzer F. Effective doses of employees at the former uranium processing plant MAPE Mydlovary, Czechoslovakia. Radiat Prot Dosimetry. 2017;175(2):171-7.

Received November 10, 2016 Accepted in revised form March 11, 2020 